\title{
ANALISIS STRUKTUR FUNGSIONAL MODEL A.J GREIMAS DALAM LEGENDA LANTING MIHING
}

\author{
(Analysis Of Functional Structure of Model A. J Greimas In Legends Lanting Mihing)
}

\author{
Kambang \\ Balai Bahasa Kalimantan Tengah \\ Jalan Tingang Km 3,5, Palangka Raya, Kalimantan Tengah, Indonesia \\ Posel: kambangaliriansyah@gmail.com
}

\begin{abstract}
Abstrak: Penelitian ini menelaah struktur Fungsional Legenda Lanting Mihing, Legenda Lating Mihing merupakan cerita rakyat dari daerah aliran sungai Kahayan. Legenda ini berkisah tentang keberanian tokoh sentral memperoleh keahlian cara membuat Lanting Mihing. Tujuan penulisan ini adalah untuk mengetahui struktur fungsional di dalam cerita Legenda Lanting Mihing. Metode dalam penulisan ini adalah metode kualitatif. Untuk mengungkap keberanian tokoh sentral ini maka menggunakan teori struktur fungsional yang dikemukakan oleh A. J. Greimas. Hasil penelitian Legenda Lanting Mihing memunculkan tokoh sentral yang bernama Bowak, ada 4 latar dalam Legenda Lanting Mihing yaitu latar tempat, waktu, sosial, dan psikologi. Amanat yang disampaikan supaya generasi muda jangan melupakan tradisi yang sudah dibuat oleh leluhur, salah satunya cara pembuatan Lanting Mihing.
\end{abstract}

Kata Kunci: lanting mihing, struktur fungsional, tema, alur, latar, dan amanat.

Abstract: This study examines the Functional structure of Model A.J Greimas In Legends Lanting Mihing. The legend of Lanting Mihing is a folklore from the Kahayan river basin. This legend revolves around the courage of the central figure gained the expertise of how to make Lanting Mihing. The purpose of this writing is to know the structure in the legend story of Lanting Mihing the method in this writing is a qualitative method. To reveal the courage of this central figure then use functional structure theory proposed by A. J. Greimas. The results of Legend Lanting Mihing research led to a central figure named Bowak, there are 4 backgrounds in Legend Lanting Mihing ie background place, time, social, and psychology. Mandate delivered so that the younger generations do not forget the traditions that have been made by the ancestors, one of which way of making Lanting Mihing.

Keywords: lanting mihing, functional structure, theme, plot, background, and mandate

\section{PENDAHULUAN}

Taum (2011) menyebut masyarakat Indonesia menghadapi dua fenomena budaya yang saling berdampingan dan bersinggungan, yaitu kebudayaan lisantradisional-kesukuan dan kebudayaan tulisan-modern-nasional. Hutomo (dalam Taum, 2011) mengatakan fenomena kebudayaan lisan-tradisional itu sebagai 'mutiara yang terlupakan' atau rekaman, transkripsi 'fosil hidup' yang keberadaannya diabaikan begitu saja. Sejalan dengan itu maka terlihatlah bahwa peran penting sastra lisan dalam kehidupan manusia modern karena berfungsi sebagai penyeimbang. Pada kehidupan masyarakat tradisional Indonesia, kegiatan bersastra pada umumnya dilakukan menggunakan bahasa daerah, disebarkan secara lisan dan diwariskan secara turun-temurun. Konsep penyebaran dan pewarisan karya sastra yang bersifat lisan dan turun-temurun itulah yang kemudian menjadi bagian dari tradisi lisan. Hampir setiap wilayah kebudayaan/suku di Indonesia memiliki tradisi lisan. Dananjaya (1991) menyebut tradisi lisan sebagai folklor. Menurutnya, 
folklor adalah bagian kebudayaan dari berbagai kolektif di dunia pada umumnya dan di Indonesia pada khususnya, yang disebarkan secara turun temurun diantara kolektif-kolektif bersangkutan, baik dalam bentuk tulisan, maupun contoh yang disertai dengan gerak isyarat atau alat pembantu pengingat. Indonesia memiliki kekayaan sastra tradisional baik itu berupa prosa maupun puisi.

Sebagian kecil tradisi lisan bahasabahasa daerah telah "diselamatkan" melalui rekaman video. Akan tetapi, yang sudah "diselamatkan" itu tidaklah berarti kalau dibandingkan dengan kekayaan tradisi lisan yang (pernah) ada (Rosidi, 1994). Kebudayaan masyarakat lama dikenal beberapa sastra lisan, di antaranya ialah peribahasa, pertanyaan tradisional, syair, pantun, dan prosa. Bentuk-bentuk kesusastraan itu diciptakan oleh masyarakat untuk memenuhi kebutuhan hidupnya, yakni sebagai alat untuk memenuhi kebutuhan hidupnya, yakni sebagai alat untuk mengekspresikan pikiran dan perasaan, serta sebagai alat menyampaikan petuah dan pendidikan (Saifuddin, 2000).

Salah satu sastra lisan yang dimiliki Kalimantan Tengah terutama suku Dayak Ngaju adalah Legenda Lanting Mihing. Legenda ini berkisah tentang keberanian Bowak sebagai tokoh sentral dalam upayanya memperoleh cara membuat Lanting Mihing, ketika rohnya di bawa oleh orang dari alam gaib, di sanalah Bowak melihat rakyat Batang Danum Telo (nama negeri khayangan) membuat lanting mihing fungsinya sebagai alat mengambil harta berharga. Lanting mihing ini dibuat dengan bahan kayu yang tidak biasa karena setiap kayu yang dipakai memiliki nama dan fungsinya masing-masing. Lanting mihing itu sendiri adalah rakit magis.

Mihing merupakan salah satu benda budaya tradisonal masyarakat Kabupaten Gunung Mas yang hampir punah. Menurut Kitab Panuturan Suku Dayak Ngaju (Kitab Suci Hindu Kaharigan) Kata mihing berasal dari bahasa Sangiang atau bahasa Sangen.
Mihing berarti semacam alat menangkap ikan yang mengandung daya mistik untuk menarik perhatian ikan-ikan, sehingga ikanikan berdatangan dan masuk ke dalam mihing. Menurut kepercayan masyarakat Dayak Ngaju, mihing juga merupakan pembawa rejeki, baik di dunia fana maupun alam baka. Ada juga yang mengenal mihing dengan sebutan mihing manasa. Manasa berati memasuki. Adapun asal mula adanya mihing dalam kehidupan suku Dayak Ngaju khusus di sungai Kahayan, sangat erat kaitannya dengan legenda cerita Rangan Mihing atau Legenda Lanting Mihing yang merujuk kepada seorang kesatria Dayak yang bernama Bowak dari desa Tumbang Danau yang merupakan wilayah kecamatan Mihing Raya.

Sepengetahuan penulis legenda Lating Mihing belum dikaji secara struktural hanya masih sebatas inventarisasi cerita oleh Barthel (1996) dalam bukunya yang berjudul Kisah Lanting Mihing dalam bentuk bahasa Dayak Ngaju dan cerita mihing dalam blog dajakbooven (2009) serta Legenda Gosong Rangan Mihing di Desa Tumbang Danau, Kecamatan Mihing Raya, Kabupaten Gunung Mas dalam blog Rusan (2013).

Masalah yang akan dikaji dalam penulisan ini adalah bagaimana struktur fungsional Legenda Lanting Mihing dan aspek struktur lainnya berupa alur, tokoh, latar, tema, dan amanat.

Kajian ini bertujuan untuk mengetahui struktur cerita Legenda Lanting Mihing. Diharapkannya hasil penulisan ini akan memberi gambaran proses tokoh utama (si Bowak) memperoleh cara membuat lanting mihing.

Penelitian legenda ini dipusatkan pada analisis struktur fungsional yang berupa alur, tokoh, latar, tema, dan amanat yang terdapat di dalamnya.

A.J. Greimas (dalam Suwondo, 2003) mengemukakan model cerita sebagai alur yang dibangun oleh berbagai tindakan yang disebut fungsi. Greimas (dalam Suwondo, 2003) mengembangkan teori berdasarkan 
analogi-analogi struktural dalam linguistik yang berasal dari Saussure. Adapun operasi fungsionalnya dibagi menjadi tiga tahap, yaitu 1) situasi awal; 2) tranformasi: tahap kecakapan, tahap utama, dan tahap kegemilangan; 3) situasi akhir.

Penulisan sejenis ini pernah dilakukan Yayuk (2013) yang berjudul Legenda Anak Durhaka: Analisis Struktur 3 Cerita Masyarakat Banjar, Kalimantan Selatan. Semantara itu dalam penulisan Analisis Struktur Fungsional Model A.J Greimas dalam Legenda Lanting Mihing ini mengkaji satu cerita dari sudut pandang yang sama. Penulisan Rissari Yayuk mengangkat tema anak durhaka sedangkan dalam penulisan artikel ini mengangkat tema keberanian tokoh utama.

Cara kerja model ini bergerak dari situasi awal ke situasi akhir, Di antara kedua situasi ini terdapat tahapan transformasi. Situasi awal meliputi (1) munculnya peran tokoh utama sebagai pembantu dari seorang majikan yang kaya raya, (2) sang tokoh mengalami banyak pengalaman, uji kecakapan dan cara membuat lanting mihing, setelah kembali ke alam manusia maka Bowak pun membuat lanting mihing, (3) hingga akhirnya lanting mihing tidak berfungsi sebagai alat mengambil harta benda berharga melainkan sebagai alat penangkap ikan. Tahap transformasi mencakup tahap pertama, kedua, dan ketiga. Tahap pertama, yakni perkenalan siapa tokoh utamanya yaitu si Bowak yang bekerja sebagai pembantu serta kebiasaanya yang nantinya menghantarkan dia menuju ke tahap kedua. uji kecakapan, seperti keberangkatan tokoh utama (subjek) dari tanah asal, menuju alam gaib, dan mengikuti sayembara. Tahap kedua adalah tahap utama, yaitu sang tokoh melewati masa perjuangan dengan segala tantangan. Tahap ini menceritakan tentang perjuangan Bowak memenangkan sayembara di negeri khayangan serta kepulangan subjek ke kampung halamanya. Tahap transformasi ketiga adalah masa kegemilangan sekaligus terbongkarnya perbuatan subjek (Bowak) yang telah mencuri ilmu teknik pembuatan lanting mihing, pada situasi akhir biasanya objek cerita akan memperoleh hukuman, balasan perbuatan yang dilakukannya. Berakhirlah cerita tersebut.

Kata legenda menurut KBBI (2016) adalah cerita rakyat pada zaman dahulu yang ada hubungannya dengan peristiwa sejarah. Legenda adalah cerita yang mempunyai ciri-ciri yang mirip dengan mite, yaitu dianggap pernah benar-benar terjadi, tetapi tidak dianggap suci. Berlainan dengan mite, legenda ditokohi manusia, walaupun ada kalanya mempunyai sifatsifat yang luar biasa, dan seringkali juga dibantu makhluk-makhluk ajaib. Tempat terjadinya adalah di dunia seperti yang kita kenal kini, karena waktu terjadinya belum terlalu lampau. Legenda adalah cerita rakyat yang dianggap oleh sang pemilik cerita sebagai suatu kejadian yang sungguhsungguh pernah terjadi. Legenda berbeda dengan mite. Legenda bersifat sekuler (keduniawian), terjadi pada masa lalu yang belum lampau dan bertempat di dunia yang dikenal sekarang (Dananjaya, 1991). Tema menurut Nurgiyantoro (2005) merupakan gagasan dasar umum yang menompang sebuah karya sastra dan yang terkandung didalam teks.

Nurgiyantoro (2005) mengungkapkan bahwa latar sebuah karya sastra berupa tempat terjadinya peristiwa dalam cerita. Latar dapat dibedakan dalam 3 unsur: 1) Latar tempat adalah menyaran pada lokasi terjadinya peristiwa yang diceritakandalam sebuah karya fiksi. 2) Latar waktu adalah latar yang berhubungan dengan masalah "kapan" terjadinya peristiwa yang diceritakan dalam sebuah karya fiksi. 3) Latar sosial adalah latar yang menyarankan pada hal-hal yang berhubungan dengan perilaku kehidupan sosial masyarakat di suatu tempat yang diceritakan dalam karya fiksi.

Tokoh dan Alur menurut Nurgiyantoro (2005) adalah tokoh cerita dalam sebuah karya fiksi dapat dibedakan kedalam 
beberapa jenis. Berdasarkan perbedaan sudut pandang dan tinjauan seorang tokoh dapat dibedakan yakni: tokoh utama dan tokoh tambahan. Tokoh utama adalah tokoh yang diutamakan, sedangkan tokoh tambahan adalah tokoh yang melengkapi dalam bentuk konflik. Plot/Alur adalah cerita yang berisi urutan kejadian, namun tiap kejadian itu hanya dihubungkan secara sebab akibat, peristiwa yang satu disebabkan atau menyebabkan terjadinya peristiwa yang lain. Amanat menurut Nurgiyantoro (2005) adalah pesan moral yang ingin disampaikan oleh pengarang.

\section{METODE PENELITIAN}

Metode yang digunakan dalam penelitian ini adalah metode kualitatif, yaitu menggunakan kata-kata atau kalimat dalam suatu struktur yang logik, untuk menjelaskan konsep-konsep dalam hubungan satu sama yang lain (Danandjaja, 1990, hlm. 98) lebih lanjut penulisan ini, bersifat deskripsi, yang artinya data terurai dalam bentuk katakata atau gambaran-gambaran dan semua hal yang berupa sistem tanda tidak ada yang diremehkan sehingga akan memberikan suatu pemahaman yang lebih komprehensif (Semi, 2012).

Adapun langkah-langkah yang dilakukan adalah sebagai berikut:

\section{Penentuan Sumber Data}

Sumber data penulis ini adalah buku (Barthel, 1996), (dajakbooven, 2009), dan (Rusan, 2013).

2. Teknik Pengumpulan Data

Data diambil dari sumber data sesuai dengan perumusan masalah. Dalam penulisan ini, penulis menggunakan simak catat, yaitu melakukan penyimakan dan pencatatan untuk mendapatkan data-data sesuai dengan kebutuhan. Selanjutnya, dilakukan pengklasifikasikan data sesuai permasalahan.

\section{Analisis Data}

Sesuai dengan perumusan masalah, analisis data ini menggunakan pendekatan struktural fungsional dan aspek struktur lainnya berupa alur, tokoh, latar, dan tema untuk mendeskripsikan struktur fungsional dalam legenda Lanting Mihing. Data yang diambil dari sumber data sesuai dengan perumusan masalah, dalam penelitian ini menggunakan teknik studi pustaka. Selanjutnya dilakukan pengklasifikasikan data sesuai permasalahan, selanjutnya proses pengolahan data analisis Legenda Lanting Mihing adalah studi pustaka, bahan yang diambil berupa teks atau naskah. Cara kerja yang dilakukan dengan membaca, simak, catat, selanjutnya pembahasan dilakukan dengan teori Greimas (dalam Suwondo, 2003) untuk mengungkapkan unsur struktur fungsional yang terdiri atas: alur, tokoh, latar, tema dan amanat.

\section{PEMBAHASAN}

\section{Ringkasan Cerita}

Konon Bowak merupakan seorang laki-laki yang sejak kecilnya hidup dengan salah satu keluarga kaya. Pekerjaan Bowak sehari-hari adalah memelihara ternak dari keluarga kaya tersebut. Bowak merupakan pekerja yang rajin dan tekun, yang mana pada suatu waktu juga lelah dan jenuh pada pekerjaanya, ketika kejenuhan itu menganggu pekerjaannya sambil mengiris batang keladi untuk makanan ternaknya tersebut dia sering bersenandung dalam bahasa sangiang, Bowak pun mulai mangarungut atau mandak, ucapan dikeluarkan Bowak waktu itu adalah "Narai kajarian kea gawi kalutuh, nasang tingang dia bahelat andau, maraga kalawet isen sankelang pandang kalaman". artinya: kapan berakhir pekerjan ini, setiap hari memotong daging burung tingang, dan mencincang daging monyet (owa-owa), sebenarnya yang dipotong dan dicincang oleh Bowak hanya batang dan daun keladi untuk makanan ternak tuanya.

Perkataannya inilah yang terdengar oleh Sangiang (Dewa Langit) di lewu Telo Kalabuan Tingang Rundung Epat Kalehulun Talawang, kedengarannya 
begitu gagah dan berani. Membuat Raja Sangiang tertarik untuk mengutus pesuruhnya Sahawung untuk menjemput Bowak ke lewu Telo (Negeri Para Sangiang/Kayangan) untuk menguji kegagahannya.

Singkat cerita Bowak pun dibawa ke Lewu Telo dan diperlakukan seperti raja dan diminta untuk tinggal beberapa lama di sana. Sehingga sampailah saat pengujian kegagahan Bowak. Pada suatu hari dia diajak oleh warga Lewu Telo (dunia Sangiang/kayangan) untuk berburu burung Tingang menggunakan Sipet/Sumpitan, yang ternyata hanya burung Endu/Punai saja menurut kita bangsa manusia, tetapi menurut bangsa Sangiang adalah Tingang dengan mudah Bowak menangkap begitu banyak burung tersebut karena dia sudah terbiasa berburu di tempat asalnya di dunia manusia (Pantai Danum Kalunen).

Keesokan harinya dia kembali diuji dan diajak menangkap ikan Tambun dengan Sahipang/Tombak. Dan alangkah terkejutnya dia ternyata ikan Tambun yang di kiranya begitu besar hanyalah ikan Pentet (Lele) saja di tempat asal Bowak. Bowak menangkap beratus-ratus ikan Tambun dengan hanya mengunakan tangan tampa harus memakai Sahipang/Tombak yang membuat Sahawung menyuruhnya berhenti menangkap ikan karena takut ikan tersebut habis dan musnah dari Lewu Telo.

Apa yang dilakuan Bowak di lewu Telo membuatnya begitu terkenal dan disegani sehingga pada saat ada rencana pembuatan Mihing di Lewu Telo dia tidak dilibatkan karena takut Bowak akan mencuri ilmunya dan nantinya akan dibawa lagi ke Lewu Pantai Kalunen/ Dunia untuk di peraktekan.

Sahawung pun berpikir bagaimana cara agar Bowak tidak melihat proses pembuat Mihing tersebut ialah menempatkan Bowak di sebuah tempat yang disebut Balai Sambah gandang Garantung Manah (balai tempat penyimpanan musik gandang garantung), di sanalah Bowak selama satu hari di tempatkan tujuannya agar pekerjaan Sahawung dan penghuni Lewu Telo tidak dilihat Bowak, tetapi dia masih bisa melihat pekerjaan mereka dan besoknya dia di pindahkan lagi ke Balai Jala Bulau Nihing Langit, atau Balai Jala Bulau Andung Nyahu dan dia berada disitu bersama Raja Singuh Batu, Tuhan Jenjan Liang ( Balai milik Patahu), tetapi Bowak tetap saja bisa melihat pekerjan Sahawung dan Penduduk Lewu Telo begitu terkejutnya Bowak ketika melihat banyaknya harta kekayaan seperti balanga, gong, emas, intan dan sebagainya masuk ke dalam Mihing tersebut yang belum sempurna dibuat. Maka mengertilah dia guna dari Mihing tersebut dan mengapa orang di Lewu Telo melarang dia melihat pembuatan lanting Mihing serta bahanbahan baku Lanting Mihing.

Kurang lebih dari 3 bulan di Lewu Telo akhirnya Bowak kembali diturunkan ke Pantai danum kalunen tempat dia berasal. Sesampainya di kampung Bowak kembali mengingat cara dan bahan membuat Mihing tersebut. Suatu hari dia pergi kehutan untuk mencari bahan membuat Mihing, adapun bahan-bahanya adalah: 1) Kayu : Kaja, Tabulus, tawe, banuang, gahung, sangkalemu, kajunjung, Kanaruhung, balawan, sungkup, dan, manggis. 2) Bambu Puring Humbang, Haur, dan Palingkau. 3) Rotan : Rotan (uei Bajungan, sigi, dan irit ). 4). Tanaman merambat/bajakah: Tengang, dan bajakan Tatau. 5) Batu: Batu Gandang,dan Batu Garatung.

Singkat cerita Mihing tersebut pun hampir selesai dibuat oleh Bowak, tiba-tiba Mihing bergoyang karena dimasuki barangbarang berharga, seperti : gong, balanga, emas, intan,dan lain-lain. Karena Mihing tersebut hanya dibangun di depan rumah Bowak. hingga membuat orang-orang disekitarnya takjub dan heran dan membuat Bowak menjadi begitu kaya raya mendadak dan Bowak pun menyuruh orang-orang di sekitarnya mengambil sebagian harta benda yang didapat dari dalam Mihingnya. 
Sebaliknya di Lewu Telo Pantai Sangiang orang-orang disana di resahkan dengan hilangnya harta benda mereka. Satu persatu harta benda mereka berlompatan keluar dan tidak dapat ditahan-tahan bahkan bila diikat pun tidak bisa, sebab ikatanya akan putus, begitu pula yang disimpan di dalam peti pun habis keluar dan hilang.

Sahawung ingin tahu penyebab harta berharga milik mereka hilang maka Sahawung pun turun ke Pantai Danum Kalunen untuk melihat apakah kejadian seperti itu karena ulah Bowak, ternyata benar. Sahawung melihat Bowak dan orang-orang kampungnya sibuk memungut harta benda mereka dari dalam mihing yang dibangun di atas tanah di depan rumahnya.

Sahawung lalu memanggil Bowak dan mengatakan sudah cukup harta yang didapat Bowak dan orang kampungnya dari Mihing tersebut, membuat mereka menjadi malas untuk bekerja, sesuai kodrat kita manusia yang harus bekerja keras untuk mendapatkan apa yang kita inginkan. Sejak saat itu Mihing di pindahkan oleh Sahawung kesebuah gosong kerikil tepatnya dipingiran sungai Kahayan yang di beri nama Rangan Mihing.

Sejak itu orang-orang di Pantai Danum Kalunen tidak diperbolehkan lagi membuat mihing di atas daratan kecuali di bangun di sungai, dan hanya boleh di masuki ikan baik besar maupun kecil. Bowak menyadari bahwa kehidupan di Pantai Kalunen tidak abadi dan harta benda pasti kita tinggalkan juga, hanya di kehidupan alam Sangiang-lah (Sorga) yang abadi. Mihing hanya dibangun di sungai Kahayan, batas wilayah dari hilir sungai Kahayan tepatnya dari desa Tangkahen, Kecamatan Banama Tingang, Kabupaten Pulang Pisau dan mudik kehulu Kahayan sampai dengan desa Rangan Mihing, Kecamatan Tewah Kabupaten Gunung Mas. Ini diperkuat dengan sejarah dan cerita dari masyarakat setempat. Hal ini juga di perkuat dengan fakta dan kaenahan pada habitat ikan Sadarin (sejenis ikan patin) hanya bisa ditemukan di wilayah aliran sungai Kahayan yang pernah dibangun Mihingnya saja, yaitu ikan sadarin ini hanya bisa di temukan di antara aliran sungai kahayan paling hilir di wilayah desa Tangkahen dan sekitarnya, sampai dengan di daerah desa Rangan Mihing dan sekitarnya untuk wilayah paling hulu. Belum ada cerita kuat yang bisa mengungkapkan mitos hubungan antara habitat ikan Sadarin dan Mihing. Mihing terakhir di bangun di sungai Kahayan adalah di desa Petak Bahandang Pada tahun 1977, setelah itu tidak pernah dibuat lagi sampai sekarang.

Tempat pertama di bangunnya mihing yakni di kampung Bowak sendiri, yaitu desa Tumbang Danau, apabila kita mudik sungai Kahayan, kampung tersebut terletak disisi kiri arah hilir, namun beberapa puluh tahun silam kampung tersebut sudah berpindah ke sebalah kanan. Dan desa ini dikenal dengan panggilan Lewu Pandih Rundung Bayang Hadean (bahasa Sangiang) Sekarang tempatnya sangat angker Karena sudah berubah menjadi Pahewan (Hutan Keramat). Kini tempat tersebut juga tinggal bekasnya saja, yang ditandai dengan pepohonan kelapa, durian ,langsat, dan pohon buah-buahan lainya yang diperkirakan umurnya mencapai \pm 500 tahun.

Menurut Tetua Adat di kampung tersebut, masih terdapat sisa-sisa kayu bahan peninggalan Mihing yang dibangun Bowak yaitu berupa kayu Tunggal pahera, Kayu Banuang . Kayu tersebut meski sudah pernah ditebang tapi berkembang dan hidup lagi.

\section{Struktur Fungsional dan Alur, Tokoh, Latar, Tema, dan Amanat Legenda}

\section{Struktur Fungsional Legenda Lanting Mihing}

Struktur fungsional legenda Lanting Mihing dapat diurai sebagai berikut:

1) Situasi awal

Cerita berawal dari perkenalan seorang tokoh kesatria Dayak yang bernama Bowak 
yang tinggal di desa Tumbang Danau wilayah aliran sungai Kahayan, kecamatan Mihing Raya, setelah pemekaran dari wilayah kecamatan Sepang, Kabupaten Gunung Mas. Bowak ini merupakan lakilaki yang sejak kecil hidup dengan salah satu keluarga kaya. Keseharian Bowak bekerja sebagai penjaga ternak tuannya.

2) Transformasi: Tahap kecakapan, tahap utama dan tahap kegemilangan

Tahap kedua ini dapat dilihat dari tindakan sang tokoh utama Bowak mengusir kejenuhan dari rutinitasnya dengan bersenandung (mangarungut atau mandak) syair yang dilagukan Bowak adalah: "Narai kajarian kea gawi kalutuh, nasang tingang dia bahelat andau, maraga kalawet isen sankelang pandang kalaman". artinya: kapan berakhir pekerjan ini, setiap hari memotong daging burung tingang, dan mencincang daging monyet (owa-owa). Padahal sebenarnya yang dipotong dan dicincang oleh Bowak hanya batang dan daun keladi untuk makanan ternak tuanya. Perkataan inilah yang di dengar oleh Sangiang (dewa Langit) di lewu telo lewu Telo Kalabuan Tingang Rundung Epat Kalehulun Talawang, sehingga kedengaranya begitu gagah dan berani. Membuat Raja Sangiang tertarik untuk mengutus pesuruhnya Sahawung Untuk menjemput Bowak ke lewu Telo (Negeri Para Sangiang/Kayangan) untuk menguji kegagahannya. Singkat cerita Bowak pun dibawa ke Lewu Telo dan diperlakukan seperti Raja dan diminta untuk tinggal beberapa lama di sana. Sehingga sampailah saat pengujian kegagahan Bowak. Pada suatu hari dia diajak oleh warga Lewu Telo (dunia Sangiang/kayangan) untuk berburu burung Tingang mengunakan Sipet/Sumpitan, yang ternyata hanya burung Endu/Punai saja menurut kita bangsa manusia, tetapi menurut bangsa Sangiang adalah Tingang. dengan mudah Bowak menangkap begitu banyak burung tersebut karena dia sudah terbiasa berburunya di tempat asalnya di dunia manusia (Pantai Danum Kalunen ).
Transformasi menuju tahap utama dilihat dari bagaimana cara Bowak mampu mengelabui orang lewu telo begitu banyak tempat Sahawung memnyembunyikan Bowak agar Bowak tidak melihat cara dan bahan pembuat Mihing tersebut Sahawung pun menempatkan Bowak di sebuah tempat yang disebut Balai Sambah gandang Garantung Manah (balai tempat Penyimpanan Musik Gandang Garantung), disitulah Bowak selama satu hari di tempatkan agar tidak bisa melihat pekerjaan Sahawung dan penghuni Lewu Telo, tetapi dia masih bisa melihat pekerjaan mereka. Keesokan harinya dia dipindahkan lagi ke Balai Jala Bulau Nihing Langit, atau Balai Jala Bulau Andung Nyahu dan dia berada disitu bersama Raja Singuh Batu, Tuhan Jenjan Liang ( Balai milik Patahu), tetapi Bowak tetap saja bisa melihat pekerjan Sahawung dan Penduduk Lewu Telo. Dan begitu terkejutnya Bowak ketika melihat begitu banyak harta kekayaan seperti balangga, gong, emas, intan dan sebagainya masuk kedalam Mihing tersebut padalah masih belum jadi dibuat. Maka mengertilah dia guna dari Mihing tersebut dan mengapa orang di Lewu Telo melarang dia melihat pembuatan dan bahan-bahanya. Berikutnya Transformasi tahap gemilang dimana Bowak kembali ke Lewu Batang Danum Kalunen dan membuat Lanting Mihing, ini dapat kita lihat pada kutipan berikut "Setelah kurang lebih dari 3 bulan di Lewu Telo akhirnya Bowak kembali diturunkan ke Pantai Danum Kalunen dimana dia berasal. Sesampainya di kampung Bowak kembali mengingat cara dan bahan membuat mihing tersebut. Pada suatu hari dia pergi kehutan untuk mencari bahan membuat Mihing, dan adapun bahanbahanya adalah: 1) Kayu : Kaja, Tabulus, tawe, banuang, gahung, sangkalemu, kajunjung, Kanaruhung, balawan, sungkup, dan, manggis. 2) Bambu Puring Humbang, Haur, dan Palingkau. 3) Rotan : Rotan (uei Bajungan, sigi, dan irit ). 4). Tanaman merambat/bajakah: Tengang, dan bajakan Tatau. 5) Batu: Batu Gandang,dan Batu 
Garatung. Singkat cerita Mihing tersebut pun hampir selesai dibuat oleh Bowak, tibatiba Mihing tersebut bergoyang karena dimasuki barang-barang berharga, seperti : gong, balanga, emas, intan,dan lain-lain. Karena Mihing tersebut hanya di bangun di depan rumah Bowak. Maka membuat orang-orang disekitarnya takjub dan heran dan membuat Bowak menjadi begitu kaya raya mendadak dan Bowak pun menyuruh orang-orang disekitarnya mengambil sebagian harata benda yang didapat dari dalam Mihingnya." Inilah tranformasi tahap gemilang seorang tokoh yang bernama Bowak dimana dia telah menciptakan sebuah Lanting Mihing tahap inilah yang kemudian membawa bowak menuju situasi akhir.

\section{3) Situasi Akhir}

Situasi akhir objek cerita dalam legenda Lanting Mihing adalah tokoh utama mendapat teguran dari sang dewa langit yatu Sahawung ini dapat kita lihat pada kutipan berikut "Sahawung lalu memanggil Bowak dan mengatakan sudah cukup harta yang didapat Bowak dan orang kampungnya dari mihing tersebut. Karena hanya akan membuat mereka malas untuk bekerja, sesuai kodrat kita manusia yang harus bekerja keras untuk mendapatkan apa yang kita inginkan. Dan pada saat itu juga Sahawung memutuskan untuk memindahkan Mihing ke sebuah gosong kerikil tepatnya di pinggir sungai kahayanyang diberi nama Rangan Mihing, sejak saat itulah alih fungsi dari lanting mihing tersebut berawal. Sekarang Lanting Mihing berfungsi sebagai penangkap ikan.

\begin{abstract}
Alur
Alur dalam Legenda Lanting Mihing ini dari segi kuantitasnya adalah alur tunggal karena cerita cerita Legenda Lanting Mihing hanya memiliki atau bersifat primer. Dari segi kualitasnya adalah alur rapat karena alur utama cerita ini tidak penyisipan alur lain.
\end{abstract}

\section{Tokoh}

Tokoh utama Legenda Lanting Mihing adalah Bowak, Bowak merupakan tokoh yang telah menurunkan ilmu pengetahuan bagaimana cara membuat lanting mihing yang diperolehnya dari Lewu Telo. Dari awal cerita, pertengahan, sampai akhir cerita tokoh Bowak selalu ada. Berikutnya tokoh bawahan dalam Legenda Lanting Mihing adalah Sahawung. Tokoh Sahawung muncul pada pertengahan cerita, tokoh Sahawung muncul dikarenakan rasa penasarannya mendengar nyanyian tokoh utama, bagian ini dapat kita lihat pada kutipan berikut: Perkatannya inilah yang terdengar oleh Sangiang (Dewa Langit) di lewu Telo Kalabuan Tingang Rundung Epat Kalehulun Talawang, sehingga kedengaranya begitu gagah dan berani. Membuat Raja Sangiang tertarik untuk mengutus pesuruhnya Sahawung Untuk menjemput Bowak ke lewu Telo (Negeri Para Sangiang/Kayangan) untuk menguji kegagahannya.

\section{Latar}

Legenda Lanting Mihing memiliki 4 Latar. 4 latar itu adalah latar tempat, lantar waktu, lantar social, dan latar psikologi.

Latar tempat dalam Legenda Lanting Mihing berada di desa Tumbang Danau yang berada di daerah aliran sungai Kahayan dan Batang Danum Lewu Telo tempat orang-orang gaib. Latar sosial yang ada dalam Legenda Lanting Mihing dapat kita lihat pada gambaran kehidupan tokoh Bowak yang tinggal sejak kecil bersama majikannya yang kaya raya. Latar sosial juga dimunculkan oleh tokoh Sawung yang berada di Batang Danum Lewu Telo kemunculan penduduk sangatlah penting karena mereka sangat dibutuhkan oleh Sahawung dalam pembuatan Lanting Mihing. Berikutnya adalah latar waktu dapat kita lihat pada kutipan berikut Setelah kurang lebih dari 3 bulan di Lewu Telo akhirnya Bowak kembali diturunkan ke Pantai danum kalunen dimana dia berasal. Latar psikologi terlihat pada tokoh Bowak yang memiliki keberanian membuat 
Lanting Mihing. Serta latar psikologi dapat kita lihat pada tokoh Sahawung yang marah karena kelakuan Bowak yang telah membuat Lanting Mihing di Batang Danum Kalunen (Bumi) sehingga akhirnya Sahawung memindahkan Lanting Mihing tersebut ke gosong kerikil tepatnya di pinggir sungai Kahayan.

\section{Tema}

Tema legenda Lanting Mihing adalah keberanian yang didapat oleh Bowak. Keberanian itu adalah mencuri ilmu teknik membuat Lanting Mihing, diketahui bahwa lanting mihing ini mengandung daya mistik untuk mendapatkan harta benda yang berharga.

\section{Amanat}

Cerita ini memberi pesan bahwa kita mesti menjaga dan melestarikan tradisi pembuatan Lanting Mihing yang sekarang mulai hilang bahkan dikatakan sudah mendekati kepunahan, kalau pun ada hanya satu atau dua orang yang bisa dan itupun sudah sepuh tidak bisa beraktifitas. Serta mengaja generasi muda untuk menjaga keseimbangan ekosistem yang ada di bumi Kalimantan Tengah. Kita mesti menyadari bahwa kehidupan di permukaan bumi ini tidak ada yang abadi bahkan harta benda pasti kita tinggalkan juga, hanya di kehidupan alam Sangiang-lah (Sorga) yang abadi.

Lanting Mihing merupakan nilai kearifan lokal masyarakat Kalimantan Tengah khususnya masyarakat Dayak Ngaju di daerah aliran suangai Kahayan. Sekarang ini realitas masyarakat Kalimantan Tengah telah mengalami pergeseran makna, terutama generas muda yang lebih senang bekerja dengan jalan praktis/pintas sehingga aspek-aspek penjagaan lingkungan diabaikan. Salah satu contoh ketidakperdulian masyarakat sekarang ini adalah teknik menangkap ikan dengan cara pengeboman dan racun (putas). Legenda Lanting Mihing mengajak kita bersama-sama menjaga habitat yang ada di sungai agar anak cucu kita nanti masih bisa merasakan kekayaan alam di Kalimantan Tengah. Lanting Mihing pun memberi kita pelajaran arti sebuah kebersamaan dan gotong-royong.

\section{PENUTUP}

Struktur fungsional ditinjau dari situasi awal meliputi (1) munculnya peran tokoh utama sebagai pembantu dari seorang majikan yang kaya raya, (2) sang tokoh mengalami banyak pengalaman, uji kecakapan dan cara membuat Lanting Mihing, setelah kembali ke alam manusia maka Bowak pun membuat Lanting Mihing, (3) hingga akhirnya Lanting Mihing tidak berfungsi sebagai alat mengambil harta benda yang berharga melainkan sebagai alat penangkap ikan. Tahap transformasi mencakup tahap pertama, kedua, dan ketiga. Tahap pertama, yakni perkenalan siapa tokoh utamanya yaitu si Bowak yang bekerja sebagai pembantu serta kebiasaanya yang nantinya menghantarkan dia menuju ke tahap kedua. uji kecakapan, seperti keberangkatan tokoh utama (subjek) dari tanah asal, menuju alam gaib, dan mengikuti sayembara. Tahap kedua adalah tahap utama, yaitu sang tokoh melewati masa perjuangan dengan segala tantangan. Tahap ini menceritakan tentang perjuangan Bowak memenangkan sayembara di negeri khayangan serta kepulangan subjek ke kampung halamanya. Tahap transformasi ketiga adalah masa kegemilangan sekaligus terbongkarnya perbuatan subjek (Bowak) yang telah mencuri ilmu teknik pembuatan Lanting Mihing, pada situasi akhir biasanya objek cerita akan memperoleh hukuman, balasan perbuatan yang dilakukannya. Berakhirlah cerita tersebut. Tema yang dimunculkan dalam Legenda Lanting Mihing adalah keberanian, dalam legenda Lanting Mihing ada 4 latar yaitu latar tempat, waktu, sosial, dan psikologi. Tokoh utama cerita ini adalah Bowak sedangan tokoh cerita bawahan adalah 
Sahawung. Amanat yaitu mengajak generasi muda untuk menjaga keseimbangan ekosistem yang ada di bumi Kalimantan Tengah. Lanting Mihing merupakan nilai kearifan lokal masyarakat Kalimantan Tengah khususnya masyarakat Dayak Ngaju di daerah aliran sungai Kahayan. Sekarang ini realitas masyarakat Kalimantan Tengah telah mengalami pergeseran makna, terutama generasi muda yang lebih senang bekerja dengan jalan praktis/pintas sehingga aspek-aspek penjagaan lingkungan diabaikan.

\section{DAFTAR PUSTAKA}

Barthel. (1996). Kisah Lanting Mihing. Palangkaraya: Dinas Pendidikan Kalimantan Tengah.

Dajakbooven. (2009). legenda-mihing.

Dananjaya, J. (1991). Foklor Indonesia:Ilmu Gosip, Dongeng, dan Lain-lain. Jakarta: Pustaka Utama Grafiti.

KBBI Daring. (2016). Diakses melalui https://kbbi.kemdikbud.go.id/entri/lege nda

Nurgiyantoro, B. (2005). Teori Pengkaji Fiksi. Yogyakarta: PN. Gajah Mada Press.

Rosidi, A. (1994). Sastera dan Budaya Kedaerahan Dalam Keindonesiaan. Jakarta: Pustaka Jaya.

Rusan, Y. (2013). Legenda Gosong Rangan Mihing di desa Tumbang Danau, Kec.Mihing Raya, Kab.Gunung Mas.

Saifuddin, M. (2000). Struktur Sastra Lisan Simeulue. Jakarta: Pusat Bahasa Departemen Pendidikan Nasional.

Semi, A. (2012). Metode Penelitian Sastra. Bandung: Angkasa.

Suwondo, T. (2003). Studi Sastra Beberapa Alternatif. Yogyakarta: PT. Hanindita Graha Widya.
Taum, Y. Y. (2011). Studi Sastra Lisan: Sejarah, Teori, Metode, dan Pendekata Disertai Contoh Penerapannya. Yogyakarta: Penerbit Lamalera.

Yayuk, R. (2013). Legenda Anak Durhaka: Analisis Struktural Tiga Cerita Lisan Masyarakat Banjar, Kalimantan Selatan. Metasastra, 6, 58-70. 